\title{
Baby Incubator Using PID Control Based on Kangaroo Mode (Kangaroo Mode and Humidity)
}

\author{
Nur Fildzah Hidayati ${ }^{\#}$, Endro Yulianto, Abd. Kholiq \\ Department of Electromedical Engineering Poltekkes Kemenkes, Surabaya \\ Jl. Pucang Jajar Timur No. 10, Surabaya, 60245, Indonesia \\ \#nfildzah17@gmail.com, endro_yulianto@yahoo.com, kawulloh@gmail.com,
}

\begin{abstract}
Baby Incubator is one of the electromedical equipment used to provide protection to premature babies or low birth weight. Baby care in the baby incubator causes separation of mother and baby. A new innovation in the care of premature babies who bring their babies and mothers closer is Kangaroo Method Management (PMK). Kangaroo method treatment aims to create emotional attachment to the baby, so that the mother will confidently take care. The research and manufacture of this module uses a method of treating baby incubator by adding a reading of the room temperature when the kangaroo mode runs at a setting of $34^{\circ} \mathrm{C}-37^{\circ} \mathrm{C}$ with the effect of room temperature at $18^{\circ} \mathrm{C}, 24^{\circ} \mathrm{C}$, and $30^{\circ} \mathrm{C}$ and setting the humidity control automatically by measuring at a temperature of $32{ }^{\circ} \mathrm{C}$, then measuring the results immediately. Sensors used to detect temperature are LM35 sensors and sensors used to detect humidity using DHT22. Based on the measurement results obtained uncertainty values on the measurement of humidity 2.1 , the measurement of temperature stability can be seen from the results of the graph which shows that the room temperature is not too influential at the temperature of the baby incubator. This study has shown the development of baby incubators to help mothers who have babies born prematurely so that they can have a good bond with how to treat skin to skin. This study has proven that its accuracy is appropriate to be used to stabilize the condition of babies born prematurely and help to treat PMK in some hospitals. In the future, this research can be made and used in small clinics in villages at low costs.
\end{abstract}

Keywords—Kangaroo Mode, Humidity, Baby Incubator

\section{INTRODUCTION}

According to WHO, premature babies are babies born alive before the 37 th week of gestation (calculated from the first day of the last menstruation). The American Academy of Pediatric takes a limit of 37 weeks to call premature. Premature babies are babies born under 37 weeks or babies weighing less than 2500 grams and treatment in premature infants is carried out in the baby incubator (Manuaba, 2008). Premature babies must get care at the baby incubator.

Baby Incubator is one of the electromedical equipment used to provide protection to premature newborns or have a low birth weight by providing stable temperature and humidity (Djoko Soeprijanto, 2013). Stable temperature regulation in the baby incubator is very necessary to prevent hypothermia or hypertermia that will occur in premature babies. Stable temperature is obtained from the heater control system, to produce a stable temperature and the precision of the author using the PID control system because the system is able to maintain the linearity of temperature settings so that premature babies are maintained in the baby incubator.

Baby care in the baby incubator causes separation of mother and newborn baby. Mothers who have premature babies or less months are found to be less confident in caring for their babies compared to mothers who have a term baby. A new innovation in the care of premature babies who bring their babies and mothers closer is Kangaroo Method Management
(PMK). Kangaroo method care aims to create an emotional attachment to the baby, so that the mother will be confident in her ability to care for the baby and feel capable and satisfied with her role as a mother (Journal of Indonesian Nursing, Volume 16 No.3, 2013).

In the treatment of the kangaroo method the problem is that premature babies are very prone to adapt to the ambient temperature outside the baby incubator so that they have difficulty doing the Kangaroo Method Care. The author aims to create a baby incubator in kangaroo mode that can be used for premature infants on the batasaa line born at 37 weeks of pregnancy with a body weight of 2500 grams without having problems with their organs.

The working principle of the baby incubator kangaroo mode is when the mother or biological family member of the baby such as father and grandmother will provide kangaroo method care by attaching and making direct physical contact to the baby, the baby incubator will automatically regulate the air flow inside. When the kangaroo chamber baby incubator mode can be opened by utilizing the regulated air flow in the baby incubator so that when the chamber is open the temperature in the baby invubator remains in a stable state. As well as when the kangaroo mode is running the skin sensor acts as a temperature parameter that will be set in the baby incubator to aim at the baby's temperature and the temperature around the baby at the same temperature. 
Based on that, the writer wants to make a PID-Based Baby Incubator Equipped with Kangaroo Mode in the hope that this baby incubator can produce a stable and precise temperature both when the baby incubator chamber is closed or open.

\section{MATERIALS AND METHODS}

\section{A. Experimental Setup}

This study uses data collection on each parameter as much as every parameter 5 times the data measurement. Then give the results of the data from the treatment

\section{1) Materials and Tool}

This study uses DHT22 sensors for humidity control, LM35 sensors for conditioning the temperature of a baby incubator, FLUKE Incu Analyzer II as a calibration with the module made.

\section{2) Experiment}

In this study, after the design is complete, the response of each tool parameter will be tested according to the tolerance range permitted in the baby incubator. In the calibration stage, the baby incubator was tested using INCU II Analyzer by testing the humidity at a temperature setting of $32^{\circ} \mathrm{C}$ with 5 measurements, for the stability of the kangaroo mode to measure at a temperature setting of $34^{\circ} \mathrm{C}$ to $37^{\circ} \mathrm{C}$ with an open chamber state and pay attention to the influence of room temperature around the baby incubator. Each parameter of the baby incubtor was calculated to validate the results of this study. Then the baby incubator is suitable.

\section{B. The Diagram Block}

Power supply provides voltage to the entire circuit block, input is also input from several sensors such as input from temperature sensors, humidity sensors, pressure sensors, and skin sensors. To beam these switches it serves to provide input settings at the baby incubator, in the form of desired temperature settings and desired modes for the use of baby incubators. At this baby incubator there are 2 modes, namely air control mode and kangaroo mode.

At the temperature sensor, after the sensor detects the temperature at the baby chamber the incubator's output from the sensor will enter the process block, the microcontroller block. The sensor used is the LM35 sensor which changes the temperature reading into a voltage that can be processed on the microcontroller. After processing the microcontroller the sensor will be forwarded to the display and heater. What is displayed on the display is the readable temperature and the temperature to be set. Whereas what will be forwarded to the heater is heater work. For the program, the author uses the PID program which if the temperature in the chamber is almost close to the temperature set by the heater strength will decrease gradually, and if the temperature in the chamber under the temperature of the automatic setting the heater strength will increase gradually.
At the humidity sensor after the sensor detects moisture at the baby incubator chamber, the output of the sensor will be forwarded to the process block or the microcontroller block. For the humidity sensor the writer uses the DHT22 sensor, the output from this sensor will be forwarded to the display showing the humidity of the room that is read inside the baby incubator chamber.

As well as for ouputan skin sensors will enter the process block and processed on the microcontroller. This skin sensor the author uses a Thermistor sensor. After processing the microcontroller, the output will be forwarded to the display and display the temperature of the baby when laying the skin sensor. The author uses the thermostat sensor for the safety of the baby incubator in the event of damage to the system so that it cannot disconnect the heater driver which causes the temperature to continue to rise. This thermostat sensor has a function to disconnect all systems in the event of damage or system error, and the output will be forwarded to the buzzer as a sign that the baby incubator has an error in the temperature system.

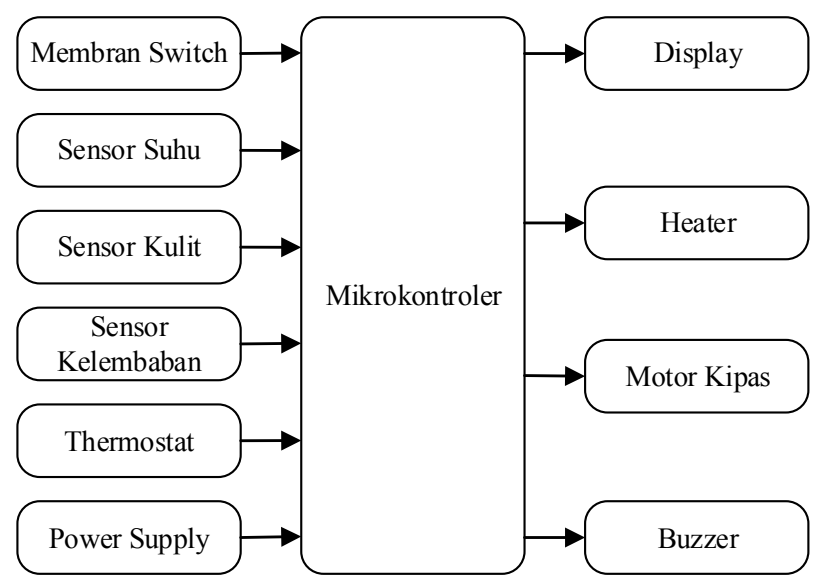

Fig 1 The diagram block of the Baby Incubator

DHT22 sensor acts as a humidity sensor, DHT22 sensor output directly into the microcontroller Digital PIN. The sensor output gives the command in the process, if the humidity that is read on the sensor is below $70 \% \mathrm{RH}$ then the heater and humidity will be active but if the humidity read on the sensor is above $70 \% \mathrm{RH}$ then the heater and fan will turn off. And the humidity value will be displayed on the display in the form of a $20 \times 4$ character LCD.

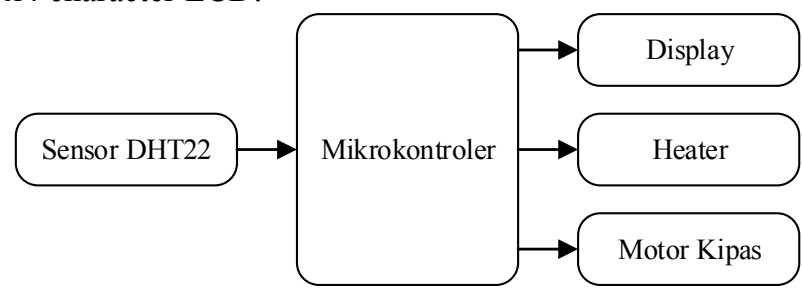

Fig. 2 The diagram block of the Humidity Control 
When the limit switch gets logic 1, the fan will turn on and vice versa if the limit switch gets logic 0 the fan will turn off.

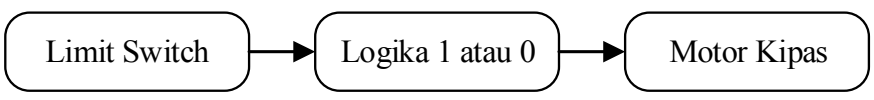

Fig 3. The diagram block of the Kangaroo Mode

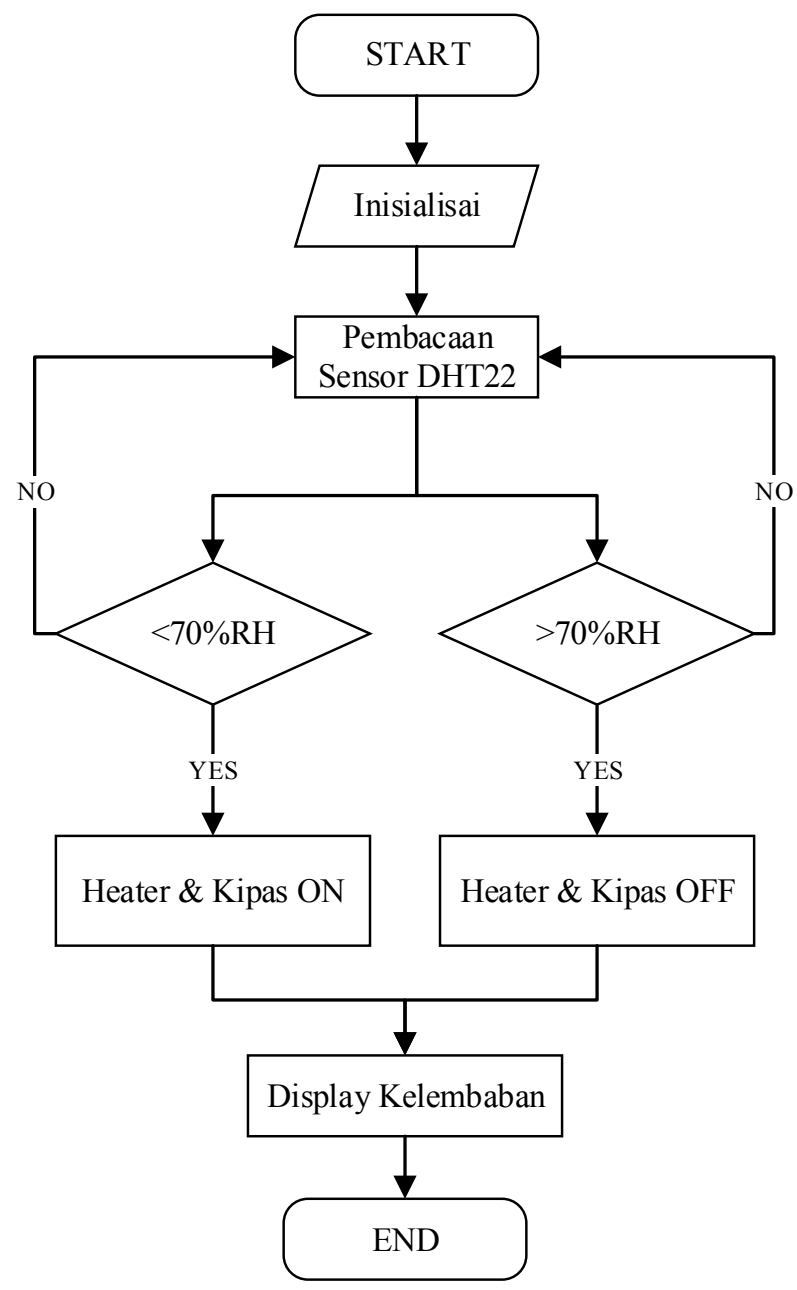

Fig 4. The Flowchart of the Humidity Control Program

\section{The Flowchart}

The Arduino program is built on the flowchart as shown in Figure. 4. After the Arduino initialization, the program asks the DHT22 sensor readings as a humidity sensor whether the humidity is read below or above $70 \% \mathrm{RH}$. If humidity is above $70 \% \mathrm{RH}$, the motor fan and heater will turn off, while if the humidity is below 70\% RH the motor fan and heater will turn on.

\section{RESULTS}

In this study, the baby incubator was tested using INCU II Analyzer and the range in each parameter was still within the tolerance range of the baby incubator.

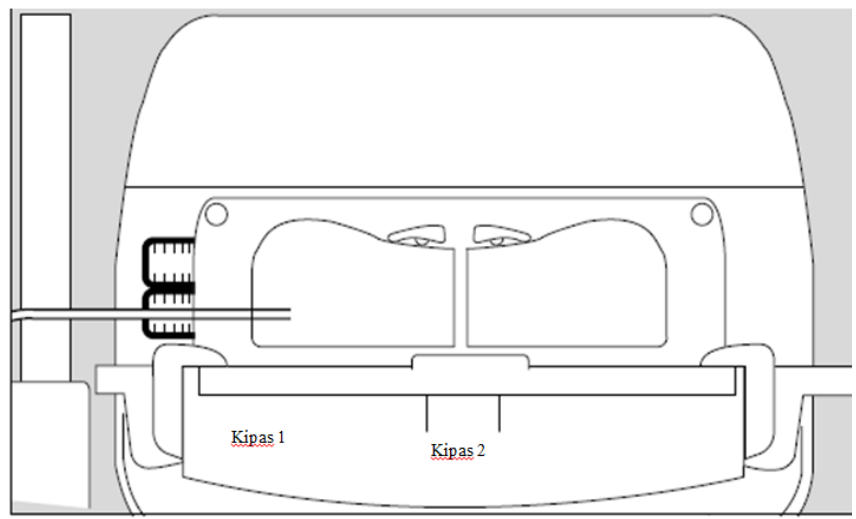

Fig 5. The Holter ECG design

\section{1) The Holter ECG Design}

Photographs of the baby incubator section are shown in figure 5, in the picture, it is seen that the device uses 2 fans, namely a fan for even distribution of the baby incubator temperature and fan 2 for kangaroo mode to create stability at the baby incubator room temperature when the chamber is open.

2) The Listing Program for Arduino Baby Incubator Humidity Control

In this paper, programming will control the work of moisture automatically.

Listing program 1. Program Humidity control

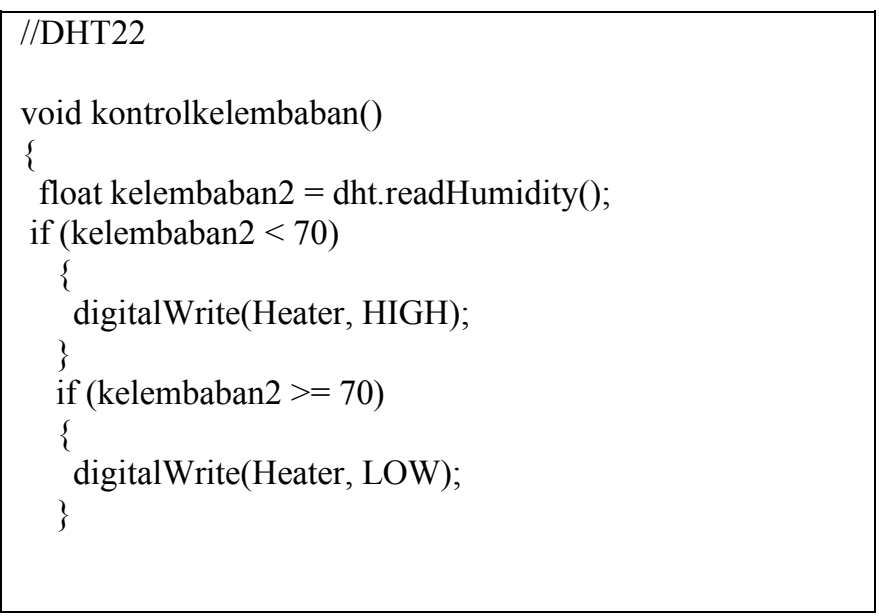

3) Kangaroo Mode with comparator INCU II Analyzer 
Before the baby incubator is said to be feasible, the device is calibrated using INCU II Analyzer.

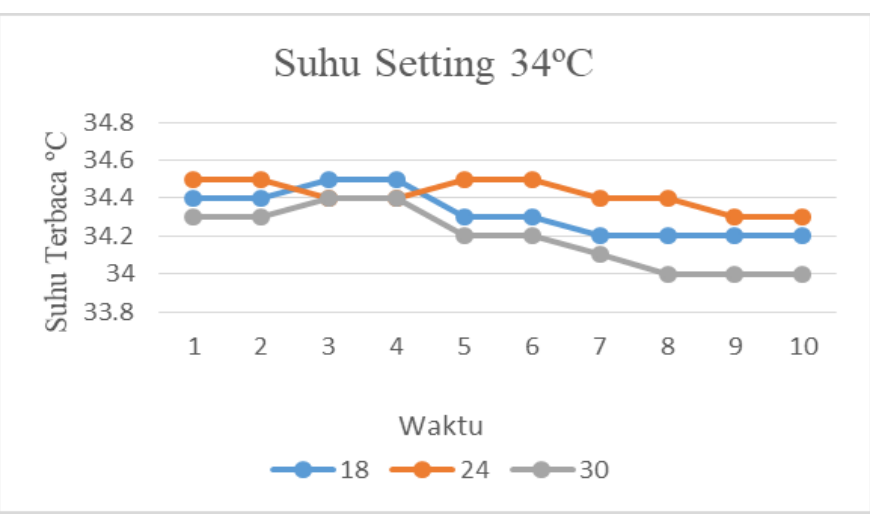

Fig 6. The Kangaroo Mode Stability Chart Temperature $34^{\circ} \mathrm{C}$

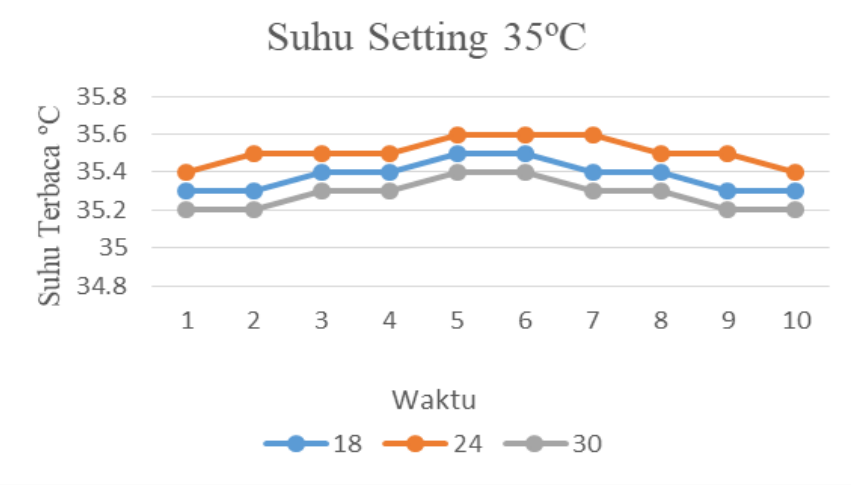

Fig 7.The Kangaroo Mode Stability Chart Temperature $35^{\circ} \mathrm{C}$

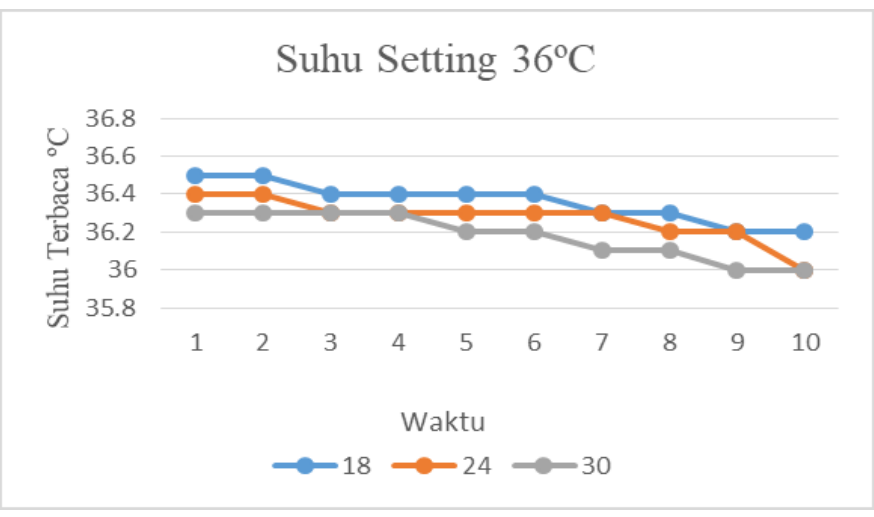

Fig 8. The Kangaraoo Mode Stability Chart Temperature $36{ }^{\circ} \mathrm{C}$

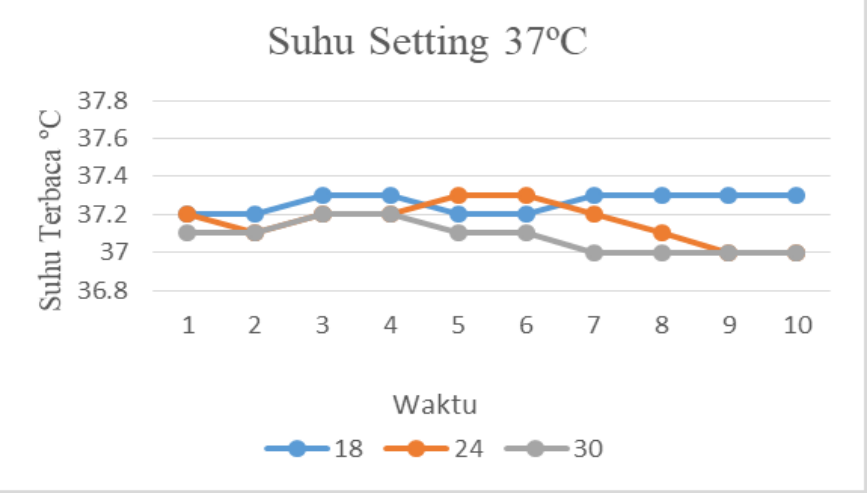

Fig. 1. The Kangaraoo Mode Stability Chart Temperature $37^{\circ} \mathrm{C}$

4) The Uncertainty of Humidity Control

The following data will display the uncertainty values obtained for the parameters of humidity in the baby incubator.

The error was showed in Table I.

TABLE I. THE UNCERTAINTY OF MEASUREMENT FOR HUMIDITY PARAMETER BETWEEN THE DESIGN AND CALIBRATOR.

\begin{tabular}{|c|c|c|}
\hline $\begin{array}{c}\text { Modul } \\
\text { Settings }\left({ }^{\circ} \mathrm{C}\right)\end{array}$ & $\begin{array}{c}\text { Standard } \\
\text { Measure } \\
(\%)\end{array}$ & Uncertanity \\
\hline $32{ }^{\circ} \mathrm{C}$ & 56.04 & 2.1 \\
\hline
\end{tabular}

\section{Discussion}

The design of the baby incubator was examined and fully tested in this study. Based on the measurement of kangaroo and humidity mode parameters, the results produced when using input from INCU II Analyzer show little difference in temperature and humidity display between design and comparator. This makes sense because each sensor has an error value and tolerance value. The uncertainty in the moisture value between the design and INCU II Analyzer shows a value of 2.1, while the measurement of kangaroo mode can be seen from the graph that at any room temperature the temperature in the baby incubator can still be stable. in open condition. This error value is suitable for use as a medical device. So that the ability to work more optimally can be added to regulate the flow of air when the baby's incubator room temperature begins to be unstable.

\section{Conclusion}

This study has shown the development of baby incubators to help mothers who have babies born prematurely so that they can have a good bond with how to treat skin to skin. This study has proven that its accuracy is appropriate to be used to stabilize the condition of babies born prematurely and help to treat PMK in some hospitals. In the future, this research can be made and used in small clinics in villages at low costs. 


\section{REFERENCES}

[1] Budiono, "Desain dan pembuatan inkubator berbasis mikrokontroler dengan logika fuzzy," vol. 9, pp. 117-123, 2013.

[2] P. Antiperovitch et al., "Primary care provider preferences for communication with inpatient teams: one size does not fit all (RL)," J. Hosp. Med., no. November, pp. 1-9, 2017.

[3] E. Emaliyawati, S. Fatimah, and Lydia, "Rate , Saturasi Oksigen pada Bayi Prematur Effect of Lullaby Music Therapy on Heart Rate, Respiration Rate , Oxygen Saturation on Prematur Infant," J. Keperawatan Padjadjaran, vol. 5, no. 3, pp. 258-270, 2017.

[4] D. Alfianto, "Pengalaman Ibu dalam Merawat Bayi dengan Prematur dan Berat Badan Lahir Rendah," NERS J. Keperawatan, vol. 9, no. 1, p. 25, 2018. 